\title{
Electroencephalographic Correlates of Sexual Arousal Induced by Sexually-Explicit Reading in Human Females
}

\author{
Miguel Angel Guevara1, Carolina Gómez-Navarro1, Claudia Amezcua-Gutiérrez ${ }^{1 *}$, \\ Marisela Hernández-González ${ }^{1}$, Anders Ågmo²
}

${ }^{1}$ Institute of Neuroscience, CUCBA, University of Guadalajara, Guadalajara, Jalisco, México

${ }^{2}$ Psychology Department, Tromsø University, Tromsø, Norway

Email: *camezcu@cencar.udg.mx

How to cite this paper: Guevara, M.A., Gómez-Navarro, C., Amezcua-Gutiérrez, C., Hernández-González, M. and Ågmo, A. (2018) Electroencephalographic Correlates of Sexual Arousal Induced by Sexually-Explicit Reading in Human Females. Journal of Behavioral and Brain Science, 8, 599-614. https://doi.org/10.4236/jbbs.2018.811037

Received: October 6, 2018

Accepted: November 4, 2018

Published: November 7, 2018

Copyright $\odot 2018$ by authors and Scientific Research Publishing Inc. This work is licensed under the Creative Commons Attribution International License (CC BY 4.0).

http://creativecommons.org/licenses/by/4.0/

\begin{abstract}
This study explored the cortical functionality in young women while reading a sexually-explicit text. Electroencephalographic activity (EEG) was recorded in heterosexual women while reading either a sexually-explicit text or one with neutral content. Absolute power (AP) and the degree of EEG synchronization among the prefrontal, temporal and parietal cortices were analyzed for the different EEG bands. To evaluate sexual arousal, valence and general activation, Likert-type and Manikin scales were applied. Subjects scored the sexually-explicit text as more pleasurable, and reported greater general activation and sexual arousal than while reading the neutral one. During reading of the sexually-explicit text only, they showed a higher AP in the beta and gamma bands in temporal areas in both hemispheres, and in the theta band in parietal ones, with a lower degree of EEG synchronization between prefronto-temporal areas in the fast bands. Results show that both hemispheres were activated in these sexually-aroused women. The low bilateral synchronization between prefrontal and temporal regions indicates the independent functionality of these cortices, which could be a requirement for inducing and maintaining sexual arousal during reading of sexually-explicit texts in women. These data should broaden our knowledge of the cortical mechanisms that underlie sexual arousal in women.
\end{abstract}

\section{Keywords}

Sexual Arousal, EEG, Sexually-Explicit Reading, Erotic Reading, Women

\section{Introduction}

In research with humans, sexual arousal (SA) is commonly induced in laboratory 
conditions by exposure to such sensory stimuli as videos, photos, audio tapes and sexually-explicit texts [1] [2] [3] [4]. Effectiveness in inducing SA varies with the type of sexual stimuli utilized and, although few studies have compared different stimuli, they have shown that sexually-explicit videos generate this condition more efficiently than photographic prints [5], slides [6] or audio tapes [1] in both men and women. This may explain why most laboratory studies have used sexual videos. However, there are some studies in which it was shown that reading erotic texts also induce sexual arousal.

Erotic, or sexually-explicit, texts (SET) have been defined as written narratives that describe and recount sexual experiences with stimulation during oral or vaginal sex and orgasm [7]. Back in the 1950s, Kinsey and colleagues [8] described that erotic reading generates SA and, more specifically, that women reported feeling sexually-aroused by reading such materials. Similarly, Osborn \& Pollak [3] measured SA in young female volunteers (aged 22 - 31 years) both subjectively-using self-report scales-and physiologically by means of a vaginal photo plethysmograph, while they read a SET. Their results showed that the high AS values self-reported by those women coincided with a higher vaginal pressure pulse.

Several functional magnetic resonance imaging (fMRI) and positron emission tomography studies have demonstrated the activation of subcortical and cortical areas during SA states and orgasm in men and women, highlighting the activation of the prefrontal, parietal and temporal cortical areas [4] [9] [10] [11]. The prefrontal cortex (PFC) is involved in evaluating and integrating neural information, in "cold" executive functions, such as planning and working memory [12] [13], and in self-regulation of sexual impulses [14] and SA [11], while the temporal lobe, where the amygdala is located, plays a pivotal role in recognizing emotions from visual stimuli [15], in emotional regulation, and in SA [4] [16]. Finally, the parietal and prefrontal cortices participate in attentional processes and the processing of relevant stimuli [17] [18], two requirements for inducing sexual arousal.

It is well-known that the perception and processing of stimuli with emotional content (such as sexual stimuli) require the activation and functional synchronization of different cortical and subcortical structures [4] [10] [19]. Though several brain structures have been associated with the detection and processing of sexual stimuli, much more information is needed concerning the neural activity and connectivity of these regions. The recording of electroencephalographic activity (EEG) is a non-invasive procedure with high temporal resolution that makes it possible to obtain information on brain functioning during different behavioral and physiological states. In humans, the frequency spectrum of EEG is divided into six bands, according to frequency: delta $(\delta, 1.5-3.5 \mathrm{~Hz})$, theta $(\theta$, $3.5-7.5 \mathrm{~Hz})$, alpha1 $(\alpha 1,7.5-10.5 \mathrm{~Hz})$, alpha2 $(\alpha 2,10.5-13.5 \mathrm{~Hz})$, beta $1(\beta 1$, $13.5-19.5 \mathrm{~Hz})$, beta $2(\beta 2,19.5-30 \mathrm{~Hz})$ and gamma $(\gamma, 31-50 \mathrm{~Hz})$. Low frequencies, such as delta, are recorded in the deeper stages of sleep and during states of motivational urges triggered by biological rewards, attention and salience detec- 
tion [20]. Theta is normally seen in drowsiness and lighter stages of sleep, as well as in pleasant [21], relaxed [22], and positive emotional states [23]. Alpha is normally recorded in awake individuals with eyes closed. A decrease in alpha is an index of increased brain activation associated with the processing of emotional responses to relevant stimuli [24]. Changes in the alpha range have been associated with attentional processes and the inhibition of irrelevant information [25], while Beta is seen under conditions of arousal [26] and increased alertness [27], or as a response to optimal sensory stimuli. The gamma band, finally, has been associated with cognitive processing and perceptual experience [28].

EEG absolute power (AP) is an index of the number of neurons that discharge synchronously; thus, it reflects the capacity for, or performance of, cortical information processing [29], whereas EEG correlations estimate the functional connectivity, or degree of synchronization, between EEG signals recorded in two different cerebral areas [30]. Studies using EEG recording have reported a lower degree of synchronization, or correlation ( $\mathrm{rEEG}$ ) between the prefrontal and posterior cortices (parietal and temporal) during sexual activation induced in young men by looking at photographs that depict sexual intercourse [19]. To date, however, few studies have examined brain functioning during SA in women [9] [10] and, as far as we know, none have recorded EEG activity during SA in women induced by erotic reading.

Thus, considering that reading SET induces a state of sexual arousal [3] [7] [8] [31], and that this state is associated with the activation of the prefrontal, parietal and temporal cortices, the aim of the present study was to characterize cortical functionality by means of EEG recording in young women while reading a SET. We hypothesized that, compared to a neutral text, while reading a SET, women would present a prevalence of the theta and fast bands in the cortical areas involved in attentional and emotional processes, including the temporal and parietal areas. Moreover, given that the prefrontal cortex plays a critical role in the "cold" executive functions and self-regulation of SA [11], we further hypothesized that the women would present a lower EEG synchronization of the fast bands between the prefrontal and posterior cortices during SA induced by reading a SET.

\section{Methods}

\subsection{Participants}

The sample consisted of 18 young, healthy, heterosexual women aged 25 - 30 (mean 23.50; $\mathrm{SE}=0.80$ ), all of them right handed and with regular menstrual cycles. All women decided participate volunteered and without compensation in a single experimental session which lasted approximately one hour. All participants were assured that confidentiality would be maintained and that they were free to withdraw from the experiment at any time without penalty. None of the women reported any previous brain disease, psychopathology, sexual dysfunction or neural injury, and none were under any type of medication or drug known to 
influence EEG recording. Subjects were asked to refrain from drinking caffeine or alcohol during the $12 \mathrm{~h}$ prior to the recording sessions. All recordings were made between post-menstrual days $4-8$. The study was approved by the Institute's Committee on Research Ethics, and complied with all APA ethical standards. Subjects were only allowed to participate after signing an informed consent form which stated that they would read erotic texts as part of the study.

\subsection{Stimuli}

Two types of texts were used, one classified as neutral, the other as sexually-explicit, based on a previous pilot study applied to 14 young heterosexual women (mean age $=23.6$ years).

The sexually-explicit text (SET) was made up of excerpts from the Fifty Shades trilogy, which was written by a woman: Fifty Shades of Gray [32], Fifty Shades Darker [33], and Fifty Shades Freed [34]. Considering that the most appealing and arousing films for women are those that depict heterosexual vaginal intercourse [35], the excerpts from these books described this sexual act performed by a young heterosexual couple, including anatomical sexual references, passionate kissing, fondling, sexual activity and sexually-explicit descriptions. The Neutral Texts (NT) were descriptions of places like cities or the interior of houses and buildings, taken from: Anne Frank, Tales from the Secret Annex [36], The Neverending Story [37], Men Who Don't Love Women [38] and Love in the Time of Cholera [39]. The excerpts from both texts had similar characteristics in terms of writing, and were connected in a way that followed a sequence so that they did not seem disjointed. Each text had a total of approximately 700 words, divided into 7 paragraphs of about $70-100$ words each. The paragraphs were presented (one-by-one) in white letters on a black computer screen at a size of $480 \times 640$ pixels. The font was Times New Roman, size 22. All participants had 30 seconds to read each paragraph, so a total reading time of 3 min per text was considered.

\subsection{Questionnaires and Scales Utilized}

To ensure that the women studied were heterosexual, they answered the Kinsey Scale [40] at the beginning of the experiment. This scale ranges from 0 (for those who identified themselves as exclusively heterosexual) to 6 (for those who self-identify as exclusively homosexual). Ranges of $1-5$ thus indicate women who recognize varying levels of desire for sexual activity with either sex, including "incidental" or "occasional" desires for sexual activity with the same sex. This study included only heterosexual women who reported scores of 0 or 1 .

The sexual functioning in women was evaluated by means of the "Female Sexual Function Index" (FSFI) [41], a 19-item questionnaire, that has been developed as a brief, multidimensional self-report instrument for assessing six different dimensions of sexual function in women (desire, arousal, lubrication, orgasm, satisfaction, and pain) as well as a total score. The scores quantifies the 
sexual experience over the past 4 weeks, on a scale of 1 to 6 , where 1 is the maximum value, and 6 the minimum or null. A score $\leq 26.55$ is classified as female sexual disfunction [42].

To obtain the measures of valence and the degree of both general and sexual arousal, each participant answered two scales immediately after finishing each text. The first was the Manikin Self-Assessment Scale (SAM) [43], a non-verbal, pictorial assessment technique that directly measures pleasure (positive and negative valence) and general arousal. For valence, images ranging from a smiling, happy figure to a frowning, unhappy one represent the pleasure dimension (stimuli rated 1 - 3 were considered "unpleasant"; 4 - 6, "neutral"; and 7 - 9, "pleasant"). General arousal was rated using images that ranged from an excited, wide-eyed figure to a relaxed, sleepy one. Here, ratings of 1 - 5 were considered "not activated", and 6 - 9 "activated". The second instrument was the Sexual Arousal Scale (SAS), which is based on the principles of the Manikin Self-Assessment Scale (a Likert-type scale). It was used to indicate the degree of subjective experience of vaginal lubrication (or sexual arousal) subsequent to reading the SET. It consists of a series of 5 drawings of smiling faces of different intensities that represent vaginal lubrication, where $1=$ no lubrication (no sexual activation) and $9=$ very high lubrication (high sexual activation). This allowed us to obtain a quantitative measure of the subjective experience of sexual arousal (see Figure 1). The utility of this scale has been demonstrated in previous studies [44].

\subsection{EEG Recordings and Procedure}

All recordings were made in a sound-attenuated room at $22^{\circ} \mathrm{C}-23^{\circ} \mathrm{C}$ between

\begin{tabular}{|c|c|c|}
\hline \multicolumn{3}{|c|}{ Valence } \\
\hline & $\overline{\mathrm{X}}$ & \pm 2 ES \\
\hline NT & 5.83 & 0.76 \\
\hline SET & ${ }^{\star} 7.27$ & 0.56 \\
\hline
\end{tabular}

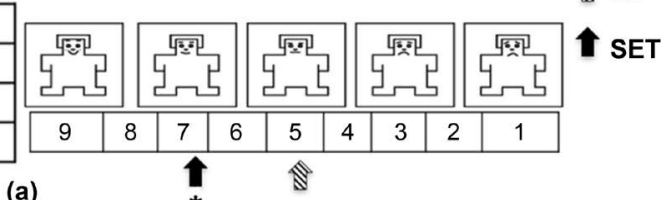

\begin{tabular}{|c|c|c|}
\hline \multicolumn{3}{|c|}{ General Arousal } \\
\hline & $\overline{\mathrm{X}}$ & $\pm 2 \mathrm{ES}$ \\
\hline NT & 3.44 & 0.96 \\
\hline SET & ${ }^{*} 6.33$ & 0.72 \\
\hline
\end{tabular}

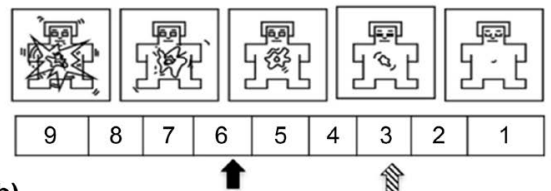

(b)

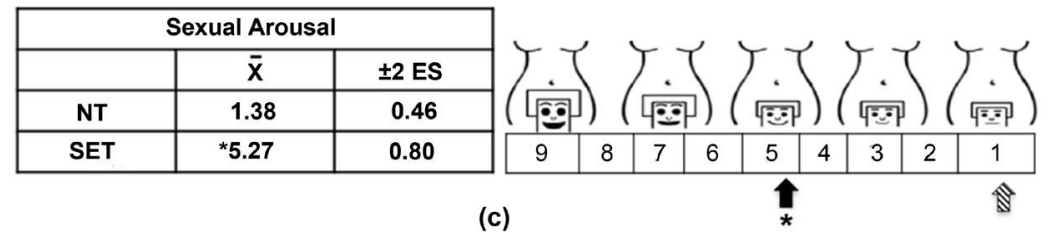

Figure 1. Statistical data and graphic representation of the subjective scores of valence (a), general arousal (b), and sexual arousal (c) reported by participants using the Manikin Self-Assessment and Sexual Arousal Scales. Wilcoxon test. ${ }^{*} \mathrm{p}(\mathrm{W}) \leq 0.01$ as compared to NT. 
10:00 and 15:00 hours and without artificial light. Electrodes were placed on the right and left prefrontal (F3, F4), temporal (T3, T4) and parietal (P3, P4) cortices according to the 10 - 20 international system [45], and referred to linked ears with impedances maintained below 10 Kohms. Linked ears were chosen as the reference to avoid, as far as possible, reference electrode and volume conduction contributions to the EEG correlations. In addition, electrooculograms were recorded to detect eye movement artifacts using a bipolar montage with electrodes placed at the outer canthi of both eyes. As a measure of peripheral activation, heart rate was simultaneously recorded by means of an electrode placed on the front of the left wrist.EEG data were recorded using a Grass P-7 polygraph (Grass Technologies, Co., USA) with filters set at 1 and $60 \mathrm{~Hz}$, digitalized at a sampling rate of $512 \mathrm{~Hz}$, and stored on a PC using CAPTUSEN acquisition software [46]. Subjects were seated in a comfortable chair in front of a laptop computer in the room with door closed. All EEG recordings were made in two conditions, each lasting 3 minutes: first while reading the neutral text and after while reading the sexually-explicit text.

EEG signals were analyzed off-line with CHECASEN software [47], which displays the EEG epochs on a computer screen. By moving 2 cursors along the EEG signals it is possible to select and store artifact-free EEG segments (caused by eye movements, muscle activity or heart beat) that correspond to the specific periods of interest. In this study, 60 epochs were selected from each text for each participant. Fast Fourier Transform (FFTs) analyses were applied to the artifact-free data in 1-s epoch samples, with the spectral graph ranging from 1 - 60 $\mathrm{Hz}$ at $1 \mathrm{~Hz}$-resolution. FFTs were performed using EEG magic software [48]. Absolute power (AP), defined as the power density of each frequency band expressed in microvolts squared $\left(\mathrm{mV}^{2} / \mathrm{Hz}\right)$, was calculated for each condition and traditional EEG band: delta, $\delta(1-3 \mathrm{~Hz})$, theta, $\theta(4-7 \mathrm{~Hz})$, alpha1, $\alpha 1(8-10$ $\mathrm{Hz})$, alpha2, $\alpha 2(11-13 \mathrm{~Hz})$, beta $1, \beta 1(14-19 \mathrm{~Hz})$, beta $2, \beta 2(20-30 \mathrm{~Hz})$, and gamma, $\gamma(31-50 \mathrm{~Hz})$. As mentioned above, EEG synchronization or correlation is a mathematical index that makes it possible to calculate the degree of similarity between two EEG signals in different frequency bands, or at specific frequencies. It is sensitive to both phase and polarity, regardless of amplitude [30]. Therefore, the correlation between cortices in the same hemisphere (intrahemispheric correlation, or rINTRA) was also calculated for each of the six frequency bands by means of Pearson Product-moment correlation analysis.

\subsection{Statistical Analyses}

The parameters of valence, general arousal and sexual arousal between conditions (NT vs. SET) were compared by Wilcox on tests.

A Student $t$ test for correlated groups was used to compare the absolute power and rINTRA of the six traditional EEG bands for the prefrontal, temporal and parietal areas in the two conditions (reading SET vs. NT). For statistical purposes, AP values were transformed into logarithms: $\ln (\mathrm{x})$, where $\mathrm{x}=\mathrm{AP}$ value in microvolts $^{2}$ [49]. Correlation values were averaged over all epochs of the same con- 
dition, for each participant and pair of derivations. To approximate a normal distribution, correlation values were transformed into Fisher's $\mathrm{Z}$ scores.

\section{Results}

\subsection{Scales}

As mentioned previously, only women who answered 0 or 1 on the Kinsey scale-i.e., exclusively heterosexual-were included. Regarding the evaluation of the texts, the results of the Manikin Self-Assessment Scale indicated significant between-condition differences (SET vs. NT) in valence $(\mathrm{W}=15.00 \mathrm{p}(\mathrm{W})=$ 0.0189), which showed that reading the SET produced more pleasure than reading the NT (Figure 1(a)). A significant difference was found for general arousal $(\mathrm{W}=0.00 \mathrm{p}(\mathrm{W})=0.0004)$ with the SET producing greater arousal than the NT (Figure 1(b)). The results of the sexual arousal scale showed that only reading the SET induced a state of SA $(\mathrm{W}=0.00 \mathrm{p}(\mathrm{W})=0.0002)$ (Figure $1(\mathrm{c})$ ).

\subsection{EEG}

\subsubsection{Absolute Power}

Statistical analyses revealed significant differences between conditions (reading SET vs. NT) in the AP of the different EEG bands. During reading of SET, higher APs of the beta $1(t=-2.47 \mathrm{p}=0.024)$, beta $2(\mathrm{t}=-2.88 \mathrm{p}=0.016)$, and gam$\mathrm{ma}(\mathrm{t}=-2.88 \mathrm{p}=0.010)$ bands in the left (T3) temporal area, and of the beta 2 $(\mathrm{t}=-2.52 \mathrm{p}=0.021)$ and gamma $(\mathrm{t}=-2.41 \mathrm{p}=0.027)$ bands in the right temporal area (T4) were observed, compared to NT (Figure 2).

In the parietal cortex, in contrast, a higher AP was obtained only during reading of the SET in both the left $(\mathrm{P} 3, \mathrm{t}=-2.573 \mathrm{p}=0.019)$ and right $(\mathrm{P} 4, \mathrm{t}=$ $-3.078 p=0.006)$ hemispheres, specifically in the theta band, compared to the NT condition (Figure 3 ).
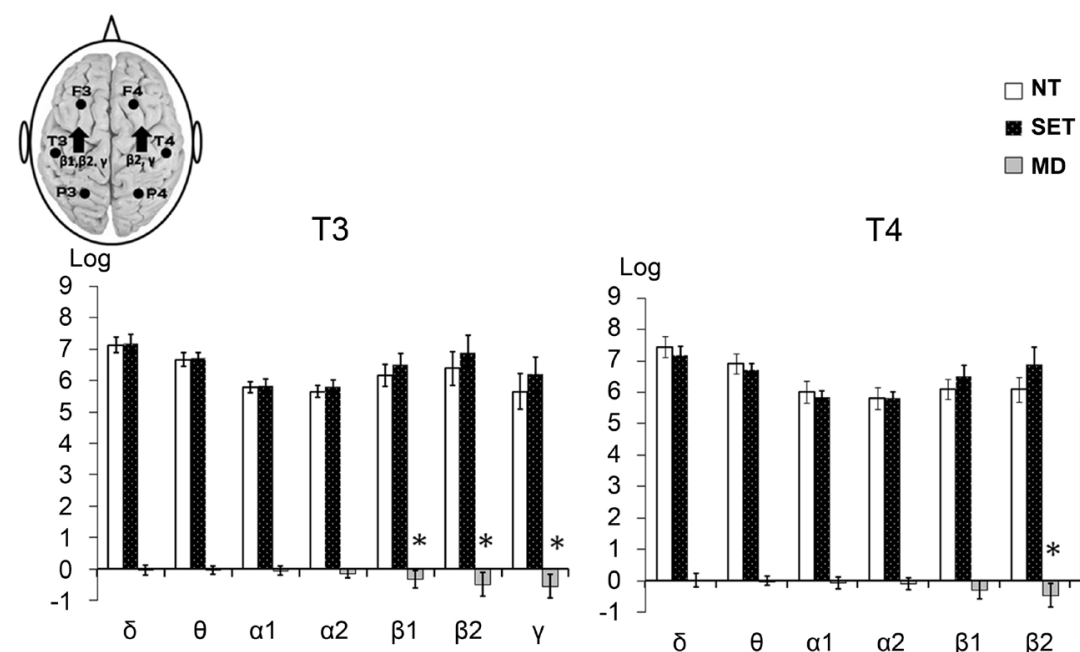

$$
\square \text { MD }
$$

T4

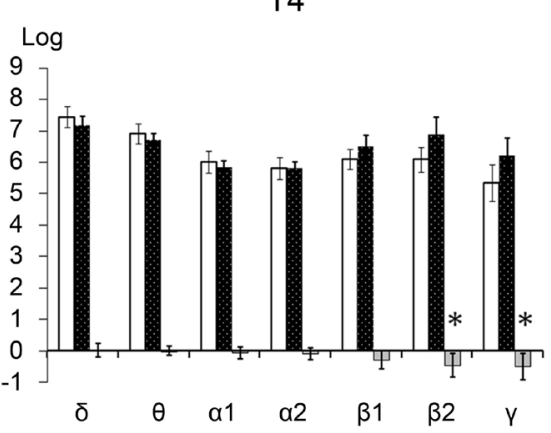

Figure 2. Absolute Power (Mean \pm 2 SE) transformed into logarithms of the EEG frequency bands recorded in temporal ( $\mathrm{T} 3$ and $\mathrm{T} 4$ ) regions of the women while reading the neutral (NT) and sexually-explicit (SET) texts. MD = Mean of differences. Students t test for correlated groups. ${ }^{\star} \mathrm{p} \leq 0.05$ as compared to NT. 


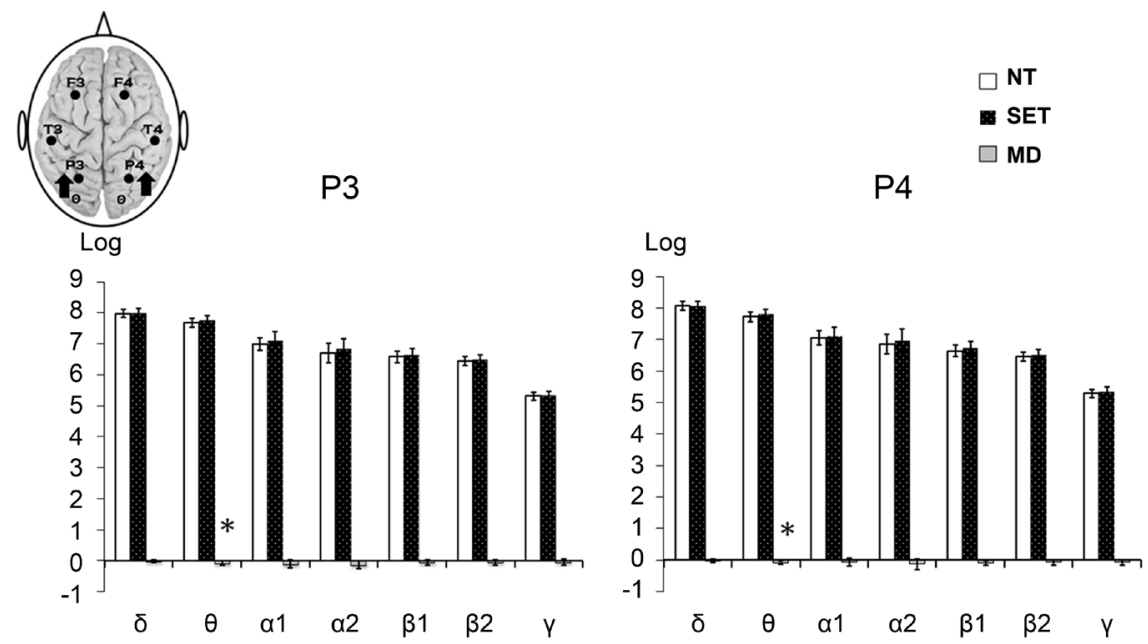

Figure 3. Absolute Power (Mean $\pm 2 \mathrm{SE}$ ) transformed into logarithms of the EEG frequency bands recorded in parietal (P3 and $\mathrm{P} 4$ ) regions of women while reading the neutral (NT) and sexually-explicit (SET) texts. $\mathrm{MD}=$ Mean of differences. Students t test for correlated groups. ${ }^{\star} \mathrm{p} \leq 0.05$ as compared to NT.
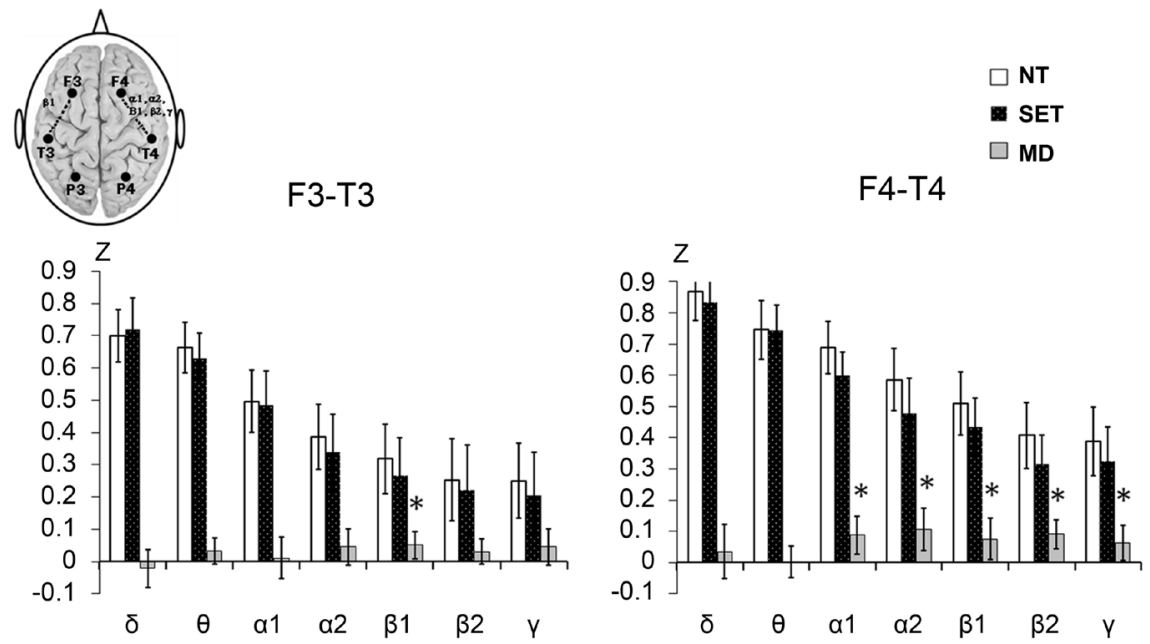

Figure 4. Intrahemispheric correlation (Mean \pm 2 SE) transformed into Fisher's Z scores of the EEG frequency bands in the left (F3-T3) and right (F4-T4)) fronto-temporal regions of the women while reading the neutral (NT) and sexually-explicit (SET) text. MD = Mean of differences. Students $t$ test for correlated groups. ${ }^{*} \mathrm{p} \leq 0.05$ as compared to NT.

No significant differences were obtained in the AP of the EEG bands in the prefrontal areas.

\subsubsection{Intra-Hemispheric Correlation}

Compared to reading the NT, the SET condition was associated with a lower degree of synchronization, or rINTRA, between the prefrontal and temporal (F3-T3) cortices. In the left hemisphere, this decreased correlation was found in beta $1(\mathrm{t}$ $=2.462 \mathrm{p}=0.024)$, whereas in the right hemisphere it was observed in the faster bands (alpha1, $\mathrm{t}=2.948 \mathrm{p}=0.008$; alpha2, $\mathrm{t}=3.114 \mathrm{p}=0.006$; beta $1, \mathrm{t}=2666$ $\mathrm{p}=0.036$; beta $2, \mathrm{t}=3.912 \mathrm{p}=0.001$; and gamma, $\mathrm{t}=2.235 \mathrm{p}=0.039$ ) (Figure 4 ). 


\section{Discussion}

To the best of our knowledge, this is the first study to characterize the cortical EEG activity of young women during sexual arousal induced by reading sexually-explicit texts. According to participants'self-reports on the Manikin and sexual arousal scales, they scored the SET as more pleasurable, and indicated that it generated greater general activation and greater sexual arousal than the NT. This result confirms reports in other studies [3] [7] [8] [31] that demonstrated the effectiveness of SET in generating a state of SA in women. Though we used an indirect, or subjective, measure-namely, vaginal lubrication self-reported on a Likert-type scale-our data are consistent with the results of other studies that have shown a direct correlation between increased vaginal pressure pulse (using vaginal photoplethysmography) and the high SA values self-reported by participants [3].

It was only while reading the SET that these women presented a greater AP in the fast bands (beta 1, beta 2 and gamma) in the temporal areas of both hemispheres. An increased AP in beta 2 and gamma has been associated with positive emotional states induced by reading [50]. In particular, the gamma band has been associated with the processing of emotional stimuli, especially in temporal areas [51]. Also, studies using imaging techniques (fMRI) have reported activation of temporal areas during states of sexual arousal induced by visual stimulation (photos, videos) in both sexes [10] [14] [52]. These findings suggest that the increased AP of the fast bands in bilateral temporal regions could be associated with the state of sexual arousal and the positive affect (greater pleasure) that the women reported after reading the sexually-explicit texts.

This study also showed a greater bilateral AP of the theta band in the parietal areas during SA. The parietal lobe has been related to attention, the integration of somatosensory and visual information [17] [18], and, through fMRI studies, to SA induced by erotic stimuli [14]. The prevalence of the theta band has been reported in the posterior cortical areas in response to emotional stimuli [53] and during pleasant and relaxed states [22]. Therefore, its prevalence in parietal areas, together with the higher AP of the fast bands in temporal areas, represent a state of cortical activation that could be associated with the affective (pleasant) evaluation and SA induced by reading sexual texts.

Contrary to our expectations, no significant differences were found in the AP of the prefrontal areas during the reading of SET compared to NT. The prefrontal cortex participates in the syntactic processing of reading; i.e., the correct combining and ordering of words in a discourse [54] and in other cognitive processes, such as working memory, concept formation [55] [56], and visual imagery [57]. All these processes are required to understand narrative texts; that is, those that combine statements to form a coherent story [58]. The stimuli used in this study were of a narrative nature, so understanding and processing the information they contained required using similar cognitive resources, ones that are modulated primarily by the prefrontal cortex. Thus, a possible explanation 
for the absence of prefrontal activation in these subjects while reading the SET could be that the processing that takes place in the prefrontal cortex while reading is similar regardless of the emotional content involved; hence, the functionality observed did not vary. A second possible interpretation is that the level of sexual arousal generated by reading the SET was insufficient to produce changes in the functionality of the prefrontal cortex, so no significant differences were found between the reading of the two texts.

Regarding the degree of EEG synchronization, or correlation between cortical areas, a lower rINTRA of the fast bands (alpha, beta) between the prefrontal and temporal cortices in both hemispheres was found only while the women read the SET. This decreased rINTRA agrees with the findings of a previous study, which found a lower prefronto-temporal correlation in beta 1 and a lower prefronto-parietal correlation in the theta and alpha2 bands in heterosexual men while observing photographs with sexual content [19]. To explain this lower intrahemispheric synchronization, several aspects must be considered. F3 and F4 specifically constitute the so-called dorsolateral region of the prefrontal cortex [59], an area related to goal-directed behavior, the evaluation and integration of neural information, and "cold" executive functions, such as planning, working memory and inhibitory control [12]. The temporal cortex, in contrast, has been widely-associated with recognizing emotions from visual stimuli [15] and several aspects of the sex drive or sexual desire [16] [60]. Moreover, it has been suggested that the inhibitory processes that are active between periods of SA, and that act to prevent its emergence, are exerted by regions in the temporal lobes [4]. On the other hand, the fast bands-beta 1, beta 2, gamma-have been related to the inter-neuronal communication of inhibitory networks [61] and to information transfer between regions [62]. Thus, it is possible that the functional dissociation between the prefrontal and temporal areas observed in our work is required to suppress any timidity or mental tasks that might interfere with the induction of the positive emotional sexual arousal associated with reading erotic texts.

Interestingly, our study did not find a lower EEG correlation between the prefrontal and parietal cortices, perhaps as a result of the cognitive processes involved in reading the texts presented. As mentioned above, understanding a narrative passage (i.e., a text with statements that form a coherent story) requires higher-order processes, such as attention and working memory [63] in which the prefrontal [7] and parietal [17] cortices play pivotal roles. In addition, an anatomical circuit described between the parietal and prefrontal areas has been widely-associated with the attentional processes responsible for achieving and maintaining sensitivity to incoming stimuli [18]. Because both texts used in this study were of a narrative nature, their reading, regardless of content, required attentional and memory processes and the integration of concepts. The fact that the prefrontal and parietal cortices participate in these processes leads us to suggest that they work together; thus explaining why a similar degree of correlation 
between them was obtained during reading of both texts.

Our results contrast with the lower prefronto-parietal correlation observed in men and women during sexual arousal induced by observing visual stimuli with sexual content (photos and videos) [19]. However, it is important to point out that visual stimulation does not require dealing with spelling, punctuation or the visual images characteristic of written language; hence, these different types of stimuli are processed distinctly. Moreover, following Anokhin et al. [9], from an evolutionary perspective, rapid assessment of a visual scene is critical for an organism's adaptation and survival, quite unlike reading, which is a reconstruction of messages represented by graphic symbols. Thus, it is not surprising to find a different functionality and degree of cortical EEG coupling during sexual arousal induced by observing visual stimuli compared to sexual arousal induced by reading texts with sexual content.

One particularly interesting result of our work is that the activation of the temporal and parietal cortices, as well as the lower prefronto-temporal correlation, were observed in both hemispheres during reading of the SET. Although numerous fRMI and EEG studies have reported distinct patterns of hemispheric lateralization during sexual activation and orgasm, mainly in men [64] [65], it is probable that a lower pattern of lateralization will be observed in women during sexual arousal, as in the case of linguistic demands. Indeed, Pugh et al. [66] and Shaywitz et al. [67] demonstrated gender-based differences in the brain regions activated by grammatical and reading tasks that indicated a stronger pattern of left-lateralization in men than women. Other works provide additional evidence of the bilateral activation of several brain structures in women during such processes as spatial orientation or language use [67] [68].

These EEG data show that during sexual arousal induced by reading erotic texts the prefrontal and parietal cortices function similarly. This is likely required for subjects to attend to cognitive demands involved in understanding and then, reasoning about, of the texts presented. The bilateral activation of the parietal and temporal areas, together with the lower EEG synchronization between prefrontal and temporal areas in both hemispheres, could be a requirement for inducing and maintaining SA during reading of sexually-explicit texts. These data should broaden our knowledge of the cerebral mechanisms that underlie sexual arousal in women.

Our study has some limitations. First, we were unable to recruit a larger sample of women, due primarily to the difficulty in finding potential subjects who fulfilled all the inclusion criteria. Second, though it has been reported that women's genital responses are similar in the laboratory and in their home environment [69], and sexual stimulation in the laboratory promotes increases in real sexual behaviors [70], it is important to consider that the laboratory situation in our study may not propitiate sexual responses comparable to those that women experience in their home environment. Hence, future research needs to explore these aspects. Finally, our study is limited by the fact that our sample 
was composed predominantly of middle-class, well-educated women who lead active sexual lives. Consequently, our findings can only be generalized to women with these characteristics.

\section{Conflicts of Interest}

The authors declare no conflicts of interest regarding the publication of this paper.

\section{References}

[1] Abel, G.G., Barlow, D.H., Blanchard, E.B. and Mavissakalian, M. (1975) Measurement of Sexual Arousal in Male Homosexuals: Effects of Instructions and Stimulus Modality. Archives of Sexual Behavior, 4, 623-629. https://doi.org/10.1007/BF01544270

[2] Julien, E. and Over, R. (1988) Male Sexual Arousal across Five Modes of Erotic Stimulation. Archives of Sexual Behavior, 17, 131-143. https://doi.org/10.1007/BF01542663

[3] Osborn, C.A. and Pollack, R.H. (1977) The Effects of Two Types of Erotic Literature on Physiological and Verbal Measures of Female Sexual Arousal. Journal of Sex Research, 13, 250-256. https://doi.org/10.1080/00224497709550982

[4] Redouté, J., Stoléru, S., Grégoire, M.C., Costes, N., Cinotti, L., Lavenne, F., Pujol, J.-F., et al. (2000) Brain Processing of Visual Sexual Stimuli in Human Males. $\mathrm{Hu}$ man Brain Mapping, 11, 162-177. https://doi.org/10.1002/1097-0193(200011)11:3<162::AID-HBM30>3.0.CO;2-A

[5] Freund, K., Langevin, R. and Zajac, Y. (1974) A Note on Erotic Arousal Value of Moving and Stationary Human Forms. Behaviour Research and Therapy, 12, 117-119. https://doi.org/10.1016/0005-7967(74)90100-4

[6] Langevin, R. and Martin, M. (1975) Can Erotic Responses Be Classically Conditioned? Behavior Therapy, 6, 350-355. https://doi.org/10.1016/S0005-7894(75)80109-2

[7] Schmidt, G., Sigusch, V. and Schäfer, S. (1973) Responses to Reading Erotic Stories: Male-Female Differences. Archives of Sexual Behavior, 2, 181-199. https://doi.org/10.1007/BF01541755

[8] Kinsey, A.C., Pomeroy, W.B., Martin, C.E. and Gebhard, P.H. (1953) Sexual Behavior in the Human Female (Vol. 1 Reimpresion 2010). Ishi Press, New York.

[9] Anokhin, A.P., Golosheykin, S., Sirevaag, E., Kristjansson, S., Rohrbaugh, J.W. and Heath, A.C. (2006) Rapid Discrimination of Visual Scene Content in the Human Brain. Brain Research, 1093, 167-177. https://doi.org/10.1016/j.brainres.2006.03.108

[10] Karama, S., Lecours, A.R., Leroux, J.M., Bourouin, P., Beaudoin, G., Joubert, S. and Beauregard, M. (2002) Areas of Brain Activation in Males and Females during Viewing of Erotic Film Excerpts. Human Brain Mapping, 16, 1-13. https://doi.org/10.1002/hbm.10014

[11] Leon-Carrion, J., Martin-Rodríguez, J.F., Damas-López, J., Pourrezai, K., Izzetoglu, K., Barroso y Martin, J.M. and Domínguez-Morales, M.R. (2007) Does Dorsolateral Prefrontal Cortex (DLPFC) Activation Return to Baseline When Sexual Stimuli Cease? Neuroscience Letters, 416, 55-60. https://doi.org/10.1016/j.neulet.2007.01.058

[12] Mega M.S. and Cummings, M.D. (2001) Frontal Subcortical Circuits. In: Salloway, 
S.P., Malloy, P.F. and Duffy, J.D., Eds., The Frontal Lobes and Neuropsychiatric Illness, American Psychiatric Association, Washington, DC, 15-32.

[13] Fuster, J.M. (1997) The Prefrontal Cortex: Anatomy, Physiology, and Neuropsychology of the Frontal Lobe. 3rd Edition, Lipincott-Raven, New York.

[14] Beauregard, M., Levesque, J. and Bourogouin, P. (2001) Neural Correlates of Conscious Self-Regulation of Emotion. Journal of Neuroscience, 21, RC165.

[15] Broks, P., Young, A.W., Maratos, E.J., Coffey, P.J., Calder, A.J., Isaac, C.L., Roberts, N., et al. (1998) Face Processing Impairments after Encephalitis: Amygdala Damage and Recognition of Fear. Neuropsychologia, 36, 59-70. https://doi.org/10.1016/S0028-3932(97)00105-X

[16] Baird, A.D., Wilson, S.J., Bladin, P.F., Saling, M.M. and Reutens, D.C. (2002) Hypersexuality after Temporal Lobe Resection. Epilepsy and Behavior, 3, 173-181. https://doi.org/10.1006/ebeh.2002.0342

[17] Wojciulik, E. and Kanwisher, N. (1999) The Generality of Parietal Involvement in Visual Attention. Neuron, 23, 747-764. https://doi.org/10.1016/S0896-6273(01)80033-7

[18] Posner, M.I. and Petersen, S.E. (1990) The Attention System of the Human Brain. Annual Review of Neuroscience, 13, 25-42. https://doi.org/10.1146/annurev.ne.13.030190.000325

[19] Hernández-González, M., Amezcua, C., Guevara, M.A. and Sanz-Martin, A. (2013) Sexual Arousal Decreases the Functional Synchronization between Cortical Areas in Young Men. Journal of Sex and Marital Therapy, 39, 1-16. https://doi.org/10.1080/0092623X.2012.665815

[20] Knyazev, G.G. (2012) EEG Delta Oscillations as a Correlate of Basic Homeostatic and Motivational Processes. Neuroscience and Biobehavioral Reviews, 36, 677-695. https://doi.org/10.1016/j.neubiorev.2011.10.002

[21] Sammler, D., Grigutsch, M., Fritz, T. and Koelsch, S. (2007) Music and Emotion: Electrophysiological Correlates of the Processing of Pleasant and Unpleasant Music. Psychophysiology, 44, 293-304. https://doi.org/10.1111/j.1469-8986.2007.00497.x

[22] Cervantes, M., Ruelas, R. and Alcala, V. (1992) EEG Signs of "Relaxation Behavior" during Breast-Feeding in a Nursing Woman. Archives of Medical Research, 23, 123-127.

[23] Aftanas, L.I. and Golocheikine, S.A. (2001) Human Anterior and Frontal Midline Theta and Lower Alpha Reflect Emotionally Positive State and Internalized Attention: High Resolution EEG Investigation of Meditation. Neuroscience Letters, 310, 57-60. https://doi.org/10.1016/S0304-3940(01)02094-8

[24] Andreassi, J.L. (2000) The Electroencephalogram (EEG): Alpha Waves. In: Psychophysiology: Human Behavior and Psychological Response, 4th Edition, Lawreance Erlbaum Associates Publishers, London, 26-27.

[25] Payne, L., Guillory, S. and Sekuler, R. (2013) Attention-Modulated Alpha-Band Oscillations Protect against Intrusion of Irrelevant Information. Journal of Cognitive Neuroscience, 25, 1463-1476. https://doi.org/10.1162/jocn_a_00395

[26] Coull, J.T. (1998) Neural Correlates of Attention and Arousal from Electrophysiology, Functional Neuroimaging and Psychopharmacology. Progress in Neurobiology, 55, 343-361. https://doi.org/10.1016/S0301-0082(98)00011-2

[27] Murthy, V.N. and Fetz, E.E. (1992) Coherent 25 to $35 \mathrm{~Hz}$ Oscillations in the Sensorimotor Cortex of Awake Behaving Monkeys. Proceedings of the National Academy of Science, 89, 5670-5674. https://doi.org/10.1073/pnas.89.12.5670 
[28] Rieder, M.K., Rahm, B., Willliams, J.D. and Kaiser, J. (2011) Human Gamma-Band Activity and Behavior. International Journal of Psychophysiology, 79, 39-48. https://doi.org/10.1016/j.ijpsycho.2010.08.010

[29] Klimesch, W. (1999) EEG Alpha and Theta Oscillations Reflect Cognitive and Memory Performance: A Review and Analysis. Brain Research Reviews, 29, 169-195. https://doi.org/10.1016/S0165-0173(98)00056-3

[30] Shaw, J.C. (1984) Correlation and Coherence Analysis of the EEG: A Selective Tutorial Review. International Journal of Psychophysiology, 1, 255-266. https://doi.org/10.1016/0167-8760(84)90045-X

[31] Jakobovits, L.A. (1965) Evaluational Reactions to Erotic Literature. Psychological Reports, 16, 985-994. https://doi.org/10.2466/pr0.1965.16.3.985

[32] James, E.L. (2011) Fifty Shades of Gray. Grijalbo, Mexico.

[33] James, E.L. (2012) Fifty Shades Darker. Grijalbo, Mexico.

[34] James, E.L. (2012) Fifty Shades Freed. Grijalbo, Mexico.

[35] Woodard, T.L., Collins, K., Perez, M., Balon, R., Tancer, M.E., Kruger, M., Diamond, M.P., et al. (2008) What Kind of Erotic Film Clips Should We Use in Female Sex Research? An Exploratory Study. The Journal of Sexual Medicine, 5, 146-154. https://doi.org/10.1111/j.1743-6109.2007.00641.x

[36] Frank, A. (2000) Anne Frank, Tales from the Secret Annex. Plaza Ijanes, Barcelona.

[37] Ende, M. (1979) The Never Ending Story. Alfaguara, Madrid.

[38] Larsson, S. (2005) Men Who Don’t Love Women. Destino, México.

[39] García Márquez, G. (1985) Love in the Time of Cholera. Sudamericana, Buenos Aires.

[40] Kinsey, A.C., Pomeroy, W.R., and Martin, C.E. (1948) Sexual Behavior in the Human Male. W.B. Saunders, Bloomington, Indiana U. Press, Philadelphia, 610-666.

[41] Rosen, R., Brown, C., Heiman, J., Leiblum, S., Meston, C., Shabsigh, R. and D 'Agostino, R. (2011) The Female Sexual Function Index (FSFI): A Multidimensional Self-Report Instrument for the Assessment of Female Sexual Function. Journal of Sex and Marital Therapy, 26, 191-208. https://doi.org/10.1080/009262300278597

[42] Wiegel, M., Meston, C. and Rosen, R. (2005) The Female Sexual Function Index (FSFI): Cross-Validation and Development of Clinical Cutoff Scores. Journal of Sex \& Marital Therapy, 31, 1-20. https://doi.org/10.1080/00926230590475206

[43] Bradley, M.M. and Lang, P.J. (1994) Measuring Emotion: The Self-Assessment Manikin and the Semantic Differential. Journal of Behavior Therapy and Experimental Psychiatry, 25, 49-59. https://doi.org/10.1016/0005-7916(94)90063-9

[44] Ruiz-Díaz, M., Hernández-González, M., Guevara, M.A., Amezcua, C. and Ågmo, A. (2012) Prefrontal EEG Correlation during Tower of Hanoi and WCST Performance: Effect of Emotional Visual Stimuli. Journal of Sexual Medicine, 9, 2631-2640. https://doi.org/10.1111/j.1743-6109.2012.02782.x

[45] Jasper, H.H. (1958) Report of the Committee on Methods of Clinical Examination in Electroencephalography. Electroencephalography and Clinical Neurophysiology, 10, 370-375. https://doi.org/10.1016/0013-4694(58)90053-1

[46] Guevara, M.A., Ramos, J., Hernández-González, M. and Corsi-Cabrera, M. (2000) CAPTUSEN: Un sistema para la adquisición computarizada del EEG y potenciales relacionados a eventos. Revista Mexicana de Psicología, 17, 7-88.

[47] Guevara, M.A., Hernández-González, M. and Sanz-Martín, A. (2010) CHECASEN: 
Programa para revisar señales EEG fuera de línea. Revista Mexicana de Ingeniería Biomédica, 31, 135-141.

[48] Guevara, M.A. and Hernández-González, M. (2009) EEGmagic: Programa para analizar señales electroencefalográficas. Revista Mexicana de Ingeniería Biomédica, 30, 41-53.

[49] Gasser, T., Bächer, P. and Möcks, J. (1982) Transformations towards the Normal Distribution of Broad Band Spectral Parameters of the EEG. Electroencephalography and Clinical Neurophysiology, 53, 119-124. https://doi.org/10.1016/0013-4694(82)90112-2

[50] Danko, S.G., Gracheva, L.V., Boytsova, Y.A. and Solovjeva, M.L. (2011) Induction of Emotional States by Reading Aloud Texts with Various Emotional Valences and Changes in the EEG Power in the $\beta$ and $\gamma$ Frequency Bands. Human Physiology, 37, 555-558. https://doi.org/10.1134/S0362119711040062

[51] Müller, M.M., Keil, A., Gruber, T. and Elbert, T. (1999) Processing of Affective Pictures Modulates Right-Hemispheric Gamma Band EEG Activity. Clinical Neurophysiology, 110, 1913-1920. https://doi.org/10.1016/S1388-2457(99)00151-0

[52] Habermeyer, B., Esposito, F., Händel, N., Lemoine, P., Klarhöfer, M., Mager, R., Graf, M., et al. (2013) Immediate Processing of Erotic Stimuli in Paedophilia and Controls: A Case Control Study. BMC Psychiatry, 13, 88 https://doi.org/10.1186/1471-244X-13-88

[53] Aftanas, L., Varlamov, A., Pavlov, S., Makhnev, V. and Reva, N. (2001) Affective Picture Processing: Event-Related Synchronization within Individually Defined Human Theta Band Is Modulated by Valence Dimension. Neuroscience Letters, 303, 115-118. https://doi.org/10.1016/S0304-3940(01)01703-7

[54] Ferstl, E.C., Neumann, J., Bogler, C. and Von Cramon, D.Y. (2008) The Extended Language Network: A Meta-Analysis of Neuroimaging Studies on Text Comprehension. Human Brain Mapping, 29, 581-593. https://doi.org/10.1002/hbm.20422

[55] Prabhakaran, V., Narayanan, K., Zhao, Z. and Gabrieli, J.D.E. (2000) Integration of Diverse Information in Working Memory within the Frontal Lobe. Nature Neuroscience, 3, 85. https://doi.org/10.1038/71156

[56] Smith, E. E. and Jonides, J. (1999) Storage and executive processes in the frontal lobes. Science, 283, 1657-1661. https://doi.org/10.1126/science.283.5408.1657

[57] Ghaem, O., Mellet, E., Crivello, F., Tzourio, N., Mazoyer, B., Berthoz, A. and Denis, M. (1997) Mental Navigation along Memorized Routes Activates the Hippocampus, Precuneus, and Insula. Neuroreport, 8, 739-744. https://doi.org/10.1097/00001756-199702100-00032

[58] Xu, J., Kemeny, S., Park, G., Frattali, C. and Braun, A. (2005) Language in Context: Emergent Features of Word, Sentence, and Narrative Comprehension. Neuroimage, 25, 1002-1015. https://doi.org/10.1016/j.neuroimage.2004.12.013

[59] Herwig, U., Satrapi, P. and Schönfeldt-Lecuona, C. (2003) Using the International 10-20 EEG System for Positioning of Transcranial Magnetic Stimulation. Brain Topography, 16, 95-99. https://doi.org/10.1023/B:BRAT.0000006333.93597.9d

[60] Herzog, A.G., Seibel, M.M., Schomer, D.L., Vaitukaitis, J.L. and Geschwind, N. (1986) Reproductive Endocrine Disorders in Women with Partial Seizures of Temporal Lobe Origin. Archives of Neurology, 43, 341-346. https://doi.org/10.1001/archneur.1986.00520040029014

[61] Whittington, M.A., Traub, R.D., Kopell, N., Ermentrout, B. and Buhl, E.H. (2000) Inhibition-Based Rhythms: Experimental and Mathematical Observations on Net- 
work Dynamics. International Journal of Psychophysiology, 38, 315-336.

https://doi.org/10.1016/S0167-8760(00)00173-2

[62] Engel, A.K. and Fries, P. (2010) Beta-Band Oscillations-Signalling the Status Quo? Current Opinion in Neurobiology, 20, 156-165.

https://doi.org/10.1016/j.conb.2010.02.015

[63] Baretta, L., Braga Tomitch, L.M., Lim, V.K. and Waldie, K.E. (2012) Investigating Reading Comprehension through EEG. Ilha do Desterro: A Journal of English Language, Literatures in English and Cultural Studies, 63, 70-99. https://doi.org/10.5007/2175-8026.2012n63p69

[64] Holstege, G., Georgiadis, J.R., Paans, A.M., Meiners, L.C., van der Graaf, F.H. and Reinders, A.S. (2003) Brain Activation during Human Male Ejaculation. Journal of Neuroscience, 23, 9185-9193. https://doi.org/10.1523/JNEUROSCI.23-27-09185.2003

[65] Wheeler, R.E., Davidson, R.J. and Tomarken, A.J. (1993) Frontal Brain Asymmetry and Emotional Reactivity: A Biological Substrate of Affective Style. Psychophysiology, 30, 82-89. https://doi.org/10.1111/j.1469-8986.1993.tb03207.x

[66] Pugh, K.R., Shaywitz, B.A., Shaywitz, S.E., Constable, R.T., Skudlarski, P., Fulbright, R.K., Gore, J.C., et al. (1996) Cerebral Organization of Component Processes in Reading. Brain, 119, 1221-1238. https://doi.org/10.1093/brain/119.4.1221

[67] Shaywitz, B.A., Shaywitz, S.E., Pugh, K.R. and Constable, R.T. (1995) Sex Differences in the Functional Organization of the Brain for Language. Nature, 373, 607. https://doi.org/10.1038/373607a0

[68] Kansaku, K., Yamaura, A. and Kitazawa, S. (2000) Sex Differences in Lateralization Revealed in the Posterior Language Areas. Cerebral Cortex, 10, 866-872. https://doi.org/10.1093/cercor/10.9.866

[69] Bloemers, J., Gerritsen, J., Bults, R., Koppeschaar, H., Everaerd, W., Olivier, B. and Tuiten, A. (2010) Induction of Sexual Arousal in Women under Conditions of Institutional and Ambulatory Laboratory Circumstances: A Comparative Study. Journal of Sexual Medicine, 7, 1160-1176. https://doi.org/10.1111/j.1743-6109.2009.01660.x

[70] Both, S., Spiering, M., Everaerd, W. and Laan, E. (2004) Sexual Behavior and Responsiveness to Sexual Stimuli Following Laboratory-Induced Sexual Arousal. Journal of Sex Research, 41, 242-259. https://doi.org/10.1080/00224490409552232 